\title{
New Skills in Education for Biodiversity Conservation in Romania
}

\author{
Maria-Mihaela ANTOFIE \\ Lucian Blaga University of Sibiu, Sibiu, Romania \\ mihaela_antofie@yahoo.com \\ Camelia SAND SAVA \\ Lucian Blaga University of Sibiu, Sibiu, Romania \\ camelia.sand@yahoo.com
}

\begin{abstract}
The purpose of this article is to analyse political and regulatory frameworks for connecting education and environment authorities in order to reveal opportunities for introducing new activities based on living organisms into the biology curriculum. The article is also proposing a conceptual framework for capacity building based on the analysis of relevant results at the international level, regarding the experiential learning process. Based on the results of this analysis Romania has the capacity to implement new activities under the public curricula for biology in order to support the development of new skills for ensuring biodiversity conservation as a whole. Moreover, at least three native species, domesticated or wild, may become subjects for next activities development under the existing curricula.
\end{abstract}

Keywords: education, new skills, biodiversity conservation, living organisms.

\section{INTRODUCTION}

The current catalyst for socio-economic development worldwide is generally represented by political commitments taken by a State or Government (Robinson, 2004). To know and understand the access to and use of natural resources is a pre-requirement imposed by the country's economic future (Jones, 2005; Tilford and Whyte, 2010). The European Summit in Lisbon set new standards for the EU economy based on sustainable development principles (Jones, 2005) and it is recognized for more than ten years the need to raise the education threshold in the European context (Tessaring and Wannan, 2010). Also these authors pointed out that training and vocational education, are integral parts of the complex process of implementing the Lisbon strategy and may have a contribution to consolidate new competencies undoubtedly supporting this process. In this context the education in classical natural science should make their contributions for this scope. As an example, 
biodiversity conservation activities, related to tourism in nature, can support new skills development

(Lordkipanidze

et

al

2005). 
Among the new skills that can support our economic development for 2020 and 2050 respectively, it may include those related to the ability to quickly engage for the balance between production and consumption and the causes that govern the study of living organisms. For biodiversity conservation issues only understanding the principles governing the organization of trophic levels, relationships between them, the logic of top down ecological balances in the trophic pyramid, relationships established into the trophic networks, all are arguments in supporting the development of new skills in the social context as a concept developed in the early ' 80 by Bill Drayton and Ed Skloot (Light, 2006). Thus, it was long time ago recognized that biology, as a natural science discipline, must find new models for supporting the development of new skills under the same competencies (Mair et al., 2006; Dees, 2007). A series of studies supports the transfer opportunity of ecological models into socio-economic life, through the development of specific entrepreneurial skills and not only, based on developing new skills up to those required for top managers (Westley et al., 2013; Koe and Majid, 2014). Tiere live project implemented in Germany between 2008 and 2010 is a positive example for experiential learning which was defined for more than 50 years ago based on pedagogical experience which now is developed as ELENA project (Sturm et al., 2014). The scope of this article is to analyse political and regulatory frameworks for introducing new activities based on living organisms into the public classes of biology considering the results of Tiere live project from Bavaria as well as of ELENA project and by taking into account our country peculiarities. The article is proposing a conceptual framework based on the analysis of relevant results at the international level regarding the introduction of new activities with living organisms as plants animals and microorganisms, into the public class.

\section{MATERIAL AND METHODS}

The study it is applied the SWOT approach to evaluate the political and regulatory frameworks for opportunities related to the introduction of new activities implying living organisms in the current curriculum of biology. The conceptual framework for capacity building is developed based on principles applied for social impact (Vanclay, 2003) and based on the reports of the Comenius Project entitled ELENA or Experiential Learning and Education for Nature Awareness no. 539561-LLP-1-2013-1-DE-COMENIUS-CMP which is a trans-European cooperative project of partners from Germany, Hungary, Romania and Georgia with the aim to promote the awareness of nature and the responsibility for nature.

\section{RESULTS AND DISCUSSION}

The implementing process of the classical and theoretical biology curriculum, in public gymnasium or high schools, needs to adapt different practical activities including that supporting biodiversity conservation, based on which new skills may further be developed according to the evolution of our society (Clark, 2001). In many countries scientists and educators signalled that the public and theoretical biology curriculum, among the natural sciences curricula, is not coupled with the progress of society and this may become a real burden for the future conservation of biodiversity (Rosenthal, 1989), mainly due to gaps into education. 


\section{Political and regulatory frameworks}

Biodiversity conservation as a concept has to be introduced into all appropriate activities supporting the implementation of biology curriculum and not only, due to the commitments taken by every country under any Multilateral Environmental Agreements (MEAs) dealing with the subjects regarding education, communication, information and awareness. The first relevant MEA is the Convention on biological diversity (CBD, 1992) ratified at the global level in 1993. The signatory Parties have assumed political commitments for the development of Communication Education and Participatory Approach tools and methods in synergy with those treaties aiming biodiversity conservation. Under the current national strategy for biodiversity conservation which also aims the implementation of Habitats Directive (92/43/EEC) and Birds Directive (409/79/EEC) there is no goal for coupling biodiversity conservation with public education system (Antofie et al., 2014). Still, to implement environmental policy commitments, Romanian authorities supported the implementation of environmental projects with external funding related to education only as extracurricular activities (Hesselink et al., 2007). However no nature restauration projects are in place and the gaps in implementing the international commitments for biodiversity conservation may be due also to the gaps in the public education (Antofie, 2012). Considering this disjunction between authorities belonging to education and environment, the Aichi Targets of the CBD's strategy are not reachable on long term if the current public education system will not adapt to news and will not include new activities in order to support the development of new skills for biodiversity conservation (Antofie et al., 2014). On the other hand the Romanian legislative framework for education is harmonized at the Community level to all Member States. If the simple institutional framework is only involving a voluntary cooperation from the schools side under the Education Law no.1/2011, the implementation of new activities under the same curriculum still needs to develop the long-term institutional framework and mostly cooperation with experts on biodiversity conservation (Antofie et al., 2014). The main form of inter-institutional cooperation in education is the partnership referred to in Art. 14, paragraph 2 of the Law no. 1/2011. Regarding the regulatory framework the schools need to comply also with the European Convention for the protection of vertebrate animals used in experimental and other scientific purposes and transposed the Directive 86/609/EEC which is specifically regulating animal species welfare (Antofie and Stettmer, 2015). Based on this set of regulatory acts, it is possible to orient specific indoor activities, which need new study kits adaptation. Milvus is the non-governmental organization which is deeply involved in the extra-curricular education on ecology, developing education kits for outdoor activities also using living organisms and the pupil proved in time to be more careful and aware about nature. And still there is no experience in implementing new activities in the existing biology curriculum to support the development of new positive emotions and skills for biodiversity conservation (Antofie et al., 2014). Based on ELENA project Romania may have the chance to pilot for the first time new activities within the classical lessons of biology following the Tiere live model, where new skills may be acquired for the protection of biodiversity. However, teachers need training for acquiring new competencies to introduce new activities in close cooperation with experts in biodiversity conservation which will be part of capacity building. 


\section{New skills development process}

In the last 20 years lot of education studies involved living organisms for teaching students and further more for exploring the competency framework starting with emotion variable, knowledge generation and the development of ethical concerns applied for ecology. Educators, pedagogues, psychologists, teachers and officials hardly contributed during time for introducing living organisms into the indoor classes. Currently an interesting approach for developing new skills based on the same curriculum for biology it is recognized to be already tested experiential learning in which the learner is directly in touch with the realities being studied (Keeton and Tate, 1978). Experiential learning is defined as the generation and/or creation of knowledge through the transformation of experience (Kolb, 1984), or furthermore as the experience involving students in doing things and in thinking about they are doing (Bonwell and Eison, 1991). The scope of developing new skills for biodiversity conservation through experiential learning is closely related to the chosen species: domestic or wild. Thus, working with domestic animals Marshall and collaborators (1998) suggested that experiential learning was effective in addressing at least two skills: hands on experience with livestock and subject cattle competence. These authors' defined cattle handling as the skill perceived to be the most important for the subject of their research or ability to handle cattle which may become important in the biodiversity conservation. It is long time recognized that effective working with living species supports the development of new skills such as understanding their behaviour and needs (Kiley-Worthington, 1990). The generation of positive emotions (e.g. interest, well-being, enjoy and satisfactions) as well as negative emotions (e.g. anxiety, anger and boredom) are part of learning process as well as cognition and motivation (Gläser-Zikuda et al., 2005). These principles were applied in one study the ECOLEapproach (Emotional and Cognitive Aspects of Learning) based on a specific combination of both student-centred and direct instruction also for biodiversity conservation. According to these authors attributions and self-concept are related to emotions generation that should be the subject of research. Moreover, these authors are reminding that internal attributions of success (e.g., having adequate ability) are related to positive achievement-related emotions being in agreement with Weiner (1985). In this regard they underlined that a negative self-concept and negative expectancies of achievements may play a relevant role in generating negative emotions such as anxiety or hopelessness. Emotions, such as interest, facilitate the implementation of activities that provide novelty or challenge, and are closely linked to all self-determined activities relevant for biodiversity conservation. Moreover, animals as healers are supported by the example given by dr. Boris Levinson using for the first time animals in the child psychotherapy and discovering by accident their positive effect in the mental process of the child cited by Kruger and Serpell in 2006. In 2010 Hummel and Randler (2010) are publishing the results for a study conducted in the Primary School and proved that the use of living animals in teaching activities are highly motivating pupils. Thus, emotional variables may have a strong impact on learning and mostly positive emotions play a key-role in the process of knowledge generation. On long term teaching it was proved that positive emotions such as well-being and interest were higher in the pupil with animal treatment where boredom was lower and scientists suggested that living animals should be used in the classroom for long-run teaching 
lessons. In Germany have been implemented new activities in physics for gymnasium where they investigated cognitive variables, cognitive-emotional variables and emotional variables related to the learning process (Laukenmann et al., 2003). They applied quantitative and qualitative methods and proved that positive emotions are more important in the acquisition phase than in the practice phase in physics supporting in this way the results of Hummel and Randler published in 2010. On contrary, it appears that anxiety plays an ambiguous role in the practice phase. Additionally, it appears that joy about learning in particular and interest are frequently linked to successful learning processes, and not merely to the nature of the subject matter. Randler and co-workers studied in 2005 in Germany the effect of living amphibians in teaching. According to these authors students who participated in the biodiversity conservation activity performed significantly better on achievement tests, and the $4^{\text {th }}$ graders performed better than the $3^{\text {rd }}$ graders, even when controlling for prior knowledge as a covariate, which also showed a significant influence. Moreover, pupils expressed high interest and well-being and low anger. In this case boredom and anxiety correlated negatively with low scores. It should be relevant to consider in this way that for biology classes in case of biodiversity conservation these authors recommend that it is relevant to focus on a small number of species, to start in primary schools to go outdoors and to be linked with common classroom teaching. Continuing this analysis it can be added that the review of Randler and co-workers (2005) describes the results of Kellert from 1985 which identified important changes in the development of children's perceptions towards animals and found distinct responses according to three age stages. Thus in the first stage (i.e. 6-9 years old) they observed changes in affective and emotional variables, in the second stage (i.e. 10-13 years old) they observed a major increase in cognitive abilities and for the last stage (i.e. 13-16 years old) it was observed a dramatic broadening of ethical concerns and ecological applications. However, the evolution of the conceptual framework for capacity building is related to the age group of students. If in the small age classes curiosity and positive emotions are essential for exploring new activities, later they are generating knowledge related to the subject within activities and in the end they develop cognitive connections to solve problems which may be considered as an asset for developing new skills under the same curriculum but implementing new activities. On the other hand it is relevant the site of learning or implementing activities became relevant for the conceptual framework. In 1998 Tunnicliffe, showed that the site where the animal specimens were observed and the manner in which they were 'available for viewing' had an important influence on the content of the conversations. The scientists are considering that farm animals, which were not exhibited elicited predominantly affective, including emotive, responses from the school groups. Later, a study published in 2003, considers that animal-based instruction is still heavily tied to traditional curricular content even from psychological point of view there it is recognized that the animal use in education may have positive effects (Cunningham, 2003). In 2008 Hammann and co-workers revealed that living plant experimentation skills may also be achieved using a germination test. Among the tested skills it can be cited: developing hypotheses, designing experiments and analysing experimental data. Thus, living organisms handling may provide almost all competencies for forming hypothesis for the next activity, designing experiment for how to handle better and analysing data directly based on direct experience. Therefore, it is relevant that the 
involved teacher to receive appropriate training for implementing new activities under the existing curriculum of biology.

\section{Proposed conceptual framework}

As a conceptual framework for capacity building at the school level it is proposed to start with the safer and easier activities, maximum three species, on the small age groups of students for being able to apply a monitoring system for the next two levels. The same lesson may be implemented for three different level of complexity according to the age stage of pupils as described above. The teachers need specialized training to implement new activities and furthermore to work together with species' experts at least in the first stage. The education system needs to support this type of cooperation also to adapt to local level needs. Based on this cooperation all activities will be developed based on the local peculiarities related to the chosen species (i.e. wolf, dog, reptiles and ants) for creating the specific learning environment. The process is not possible to be realized directly at the national level but at a small scale to pilot different activities related to living organisms according to Tiere live model can be (Sturm et al., 2014). The piloting process may be realized but not as a compulsory activity and the teacher needs the signed agreements of parents for ensuring the safety of the pupils. Also, teachers need to know each pupil for their existing phobia in order to avoid the expression of negative emotions. The successful implementation of the results of new activities into the indoor class involving living animals may be used as a threshold for ensuring their further implementation in the public schools. In case of wild native species, it is relevant that the teacher to provide first scientific movies presenting their natural habitats and after that they may implement other activities. In terms of human resources the county inspectorates will become a pivotal element for ensuring the monitoring system of the process.

\section{CONCLUSIONS}

Based on this study it is possible in Romania with the support of ELENA project to further develop the education conceptual framework for capacity building at the public school level for implementing new activities implying living organisms under the biology curriculum. Indoor activities involving at least three species may be sufficient for connecting biology and ecology for ensuring the achievement of new skills for pupils that will be involved in the future in biodiversity conservation. Teachers will need training for implementing new activities and for communicate with biodiversity conservation experts.

\section{ACKNOWLEDGEMENT}

The study was financially supported by the EU Project 539561-LLP-1-2013-1-DECOMENIUS-CMP.

\section{REFERENCES}


Antofie M.M., Sava C., Mara D., \& Gheoca V. (2014). Studiu naţional privind introducerea modelului de educaţie în şcoli cu animale vii în România /Baseline Study regarding the implementation of Biodiversity Education using Living Animals in Schools in Romania, Publishing House Lucian Blaga University Sibiu, ISBN ISBN 978-606-12-08104, $62 \mathrm{p}$.

Antofie M., \& Stettmer C. (2015). ELENA Project - International study and Comparative report, 2015. www.elena-project.eu

Bonwell, C. C., \& Eison, J. A. (1991). Active Learning: Creating Excitement in the Classroom. 1991 ASHE-ERIC Higher Education Reports. ERIC Clearinghouse on Higher Education, The George Washington University, One Dupont Circle, Suite 630, Washington, DC 20036-1183.

Clark, T. W. (2001). Developing Policy-Oriented Curricula for Conservation Biology: Professional and Leadership Education in the Public Interest.Conservation Biology, 15(1), 31-39.

Cunningham, P. F. (2003). Animal Use, Student Choice, and Nonanimal Alternatives at “America's Best” Undergraduate Colleges. Teaching of Psychology, 30(4), 288-296.

Dees, J. G. (2007). Taking social entrepreneurship seriously. Society, 44(3), 24-31.

Gläser-Zikuda, M., Fuß, S., Laukenmann, M., Metz, K., \& Randler, C. (2005). Promoting students' emotions and achievement-Instructional design and evaluation of the ECOLE-approach. Learning and Instruction, 15(5), 481-495.

ELENA project, (2015) http://www.elena-project.eu/

Hammann, M., Phan, T. T. H., Ehmer, M., \& Grimm, T. (2008). Assessing pupils' skills in experimentation. Journal of Biological Education, 42(2), 66-72.

Hesselink, F., Goldstein, W., van Kempen, P. P., Garnett, T., \& Dela, J. (2007). Communication, Education and Public Awareness (CEPA). In A toolkit for National Focal Points and NBSAP Coordinators. Secretariat of the Convention on Biological Diversity and IUCN: Montreal, Canada (p. 310).

Hummel, E., \& Randler, C. (2010). Experiments with living animals-effects on learning success, experimental competency and emotions. Procedia-Social and Behavioral Sciences, 2(2), 3823-3830.

Jones, H. C. (2005). Lifelong learning in the European Union: whither the Lisbon Strategy?. European Journal of Education, 40(3), 247-260.

Keeton, M. T., \& Tate, P. J. (Eds.). (1978). Learning by Experience-What, Why, How (No. 1). Jossey-Bass.

Kruger, K. A., \& Serpell, J. A. (2006). Animal-assisted interventions in mental health: Definitions and theoretical foundations. Handbook on animal-assisted therapy: Theoretical foundations and guidelines for practice, 2, 21-38.

Kiley-Worthington, M. (1990). Animals in circuses and zoos: Chiron's world. Little Eco-Farms Publishing.

Koe, W. L., \& Majid, I. A. (2014). A Model for Predicting Intention towards Sustainable Entrepreneurship. Business and Management, 6(2).

Kolb, D.A. (1984), Experiential education: experience as the source of learning and development. Englewood Cliffs, NJ: Prentice Hall 
Laukenmann, M., Bleicher, M., Fuß, S., Gläser-Zikuda, M., Mayring, P., \& von Rhöneck, C. (2003). An investigation of the influence of emotional factors on learning in physics instruction. International Journal of Science Education,25(4), 489-507.

Levinson B. (1972) Companion animals and human development, Springfiled IL., Charles C. Thomas.

Light, P. C. (2006). Reshaping social entrepreneurship. Stanford Social Innovation Review, 4(3), 47-51.

Lordkipanidze, M., Brezet, H., \& Backman, M. (2005). The entrepreneurship factor in sustainable tourism development. Journal of Cleaner Production, 13 (8), 787-798.

Mair, J., Robinson, J., \& Hockerts, K. (Eds.). (2006). Social entrepreneurship. New York: Palgrave Macmillan.

Marshall, T. T., Hoover, T. S., Reiling, B. A., \& Downs, K. M. (1998). Experiential learning in the animal sciences: effect of 13 years of a beef cattle management practicum. Journal of animal science, 76(11), 2947-2952.

Randler, C., Ilg, A., \& Kern, J. (2005). Cognitive and emotional evaluation of an amphibian conservation program for elementary school students. The Journal of Environmental Education, 37(1), 43-52.

Robinson, J. (2004). Squaring the circle? Some thoughts on the idea of sustainable development. Ecological economics, 48(4), 369-384.

Rosenthal, D. B. (1989). Two approaches to science-technology-society (S-T-S) education. Science education, 73(5), 581-589.

Sturm P., Adelmann W., Berthold T and Stettmer C. (2014). Baseline Study on Biodiversity Education using Living Animals in Schools in Germany on the example of the State of Bavaria. ELENA Project Experiential learning and Education for Nature Awareness. http://elena-project.eu/index.php/results-and-downloads/studies

Tessaring, M., \& Wannan, J. (2010). Vocational education and training: Key to the future. Lisbon-Copenhagen-Maastricht: Mobilising for.

Tilford, S., \& Whyte, P. (2010). The Lisbon Scorecard X: The Road to 2020. London: Centre for European Reform.

Tunnicliffe, S. D. (1998). Down on the farm: The content of conversations generated by school children viewing live animals as exhibits and on a farm.Journal of Elementary Science Education, 10(1), 1-17.

Vanclay, F. (2003). International principles for social impact assessment.Impact assessment and project appraisal, 21(1), 5-12.

Weiner, B. (1985). An attributional theory of achievement motivation and emotion. Psychological Review, 92(4), 548-573.

Westley, F. R., Tjornbo, O., Schultz, L., Olsson, P., Folke, C., Crona, B., \& Bodin, Ö. (2013). A Theory of Transformative Agency in Linked Social-Ecological Systems. Ecology \& Society, 18(3). 